ArtefaCToS. Revista de estudios de la ciencia y la tecnología

eISSN: $1989-3612$

Vol. 9, No. 2 (2020), 2. a Época, 51-77

DOI: https://doi.org/10.14201/art2020925177

\title{
Quantifiers and Ontological Fluctuations: A Dialogical and Dynamical Point of View of Existence
}

\section{Cuantificadores y fluctuaciones ontológicas: un punto de vista di- alógico y dinámico de la existencia}

\section{Juan REDMOND}

Universidad de Valparaíso, Chile

juan.redmond@uv.cl

Recibido: 15/09/2020. Revisado: 20/10/2020. Aceptado: 21/10/2020

\begin{abstract}
The objective of this article is, from the notion of existence as a function of choice, to propose a dynamic quantifier capable of capturing ontological slides or fluctuations within a logical proof. Indeed, we call ontological sliding the passage from indetermination to the ontological determination of the singular terms involved in a proof. Both notions will be presented in the pragmatic approach of Dialogics that, due to its dual semantics, allows to handle both questions in an optimal fashion.
\end{abstract}

Keywords: dialogic; dynamic; quantifier; existence; fictions.

\section{Resumen}

El objetivo del presente artículo es, a partir de la noción de existencia como función de elección, proponer un cuantificador dinámico capaz de capturar los deslizamientos ontológicos dentro de una prueba lógica. En efecto, llamamos deslizamiento ontológico al paso de la indeterminación a la determinación ontológica de los términos singulares involucrados en una prueba. ambas nociones serán presentadas en el enfoque pragmático de la dialógica que por su semántica dual permite llevar ambas cuestiones de manera idónea.

Palabras clave: dialógica; dinámica; cuantificador; existencia; ficciones. 


\section{On what there is}

Are there fictions or not? When we think that most of humans in this part of the world have shared their lives with Santa Claus, Hamlet, flying storks delivering babies, dragons, James Bond, etc., the question seems absurd. We might respond that we personally know more fictions than humans. However, with the same conviction, we attribute to them what is generally considered its most significant feature: the non-existence. Since our childhood, then, we spent our time with things that do not exist. With existence we refer to things that intuitively occur in space and time. And we are willing to accept that they include the ecuador and the axis of the earth. But what makes dragon's Song of the Nibelungen a fiction, unlike this cat purring now between my legs as I write, is that the dragon does not inhabit the space-time universe. To reassure children we say: dragons do not exist.

But at the same time we deal often with existing objects hard to repair in reality. In fact, space and time are so restricted to humans, if we do not go through these limitations, certain common knowledge would be impossible. Especially when it comes to atoms, DNA strands, historical characters already dead for centuries, etc.

Although on different occasions examples of mythology and literature have been used as a significant source of enigmas and counterexamples that have served to guide the development of different theories, fiction has always been considered a secondary issue in philosophy. Indeed, those who have dealt and are still dealing with this issue share a more or less widespread assumption about the nature of fictions: they are strange, unusual and quite different from ordinary things that surround us in our work or in our house.

Philosophical concerns with regard to fiction are generally of two types: semantic and ontological. The semantic point of view questions whether it is necessary to resort to fictional entities to give meaning to a part of natural language. And even if this were recognised as mandatory, it would be necessary to explain how it is that certain components of phrases refer to entities as difficult to situate as fictional entities.

In other words, returning to the initial question, how is it possible that there are things that do not exist? Is it that existence is a predicate of objects? What is problematic in this question points directly to the notion of non-existent objects, in particular those which conform to the perspective of Hume:

The idea of existence, then, is the very same with the idea of what we conceive to be existent. To reflect on any thing simply, and to reflect on it as existent, are nothing different from each other. That idea, when conjoined with the idea of any object, makes no addition to it. Whatever we 
conceive, we conceive to be existent. Any idea we please to form is the idea of a being; and the idea of a being is any idea we please to form. (Hume, 2000, Book I, Part II, Section VI)

In other words, for Hume to think of an object is to think of something existent. To think of an object and to think of an existent object are equivalent. From this, the concept of an object would include the concept of existence and, hence, the concept of a non-existent object would be a contradiction. Hume's ideas are present in the work of Immanuel Kant (Kant, 1781/1789. B626, 627/A598, 599). But Kant, unlike Hume, rejects the idea that existence is a real predicate of objects. Kant focuses on demolishing the ontological argument that claimed that existence could not be present in the concept of god - the being which brings all perfections together. In this sense, to think about god is to think about an existent god. The Kantian response is often seen as anticipating the semantics as elaborated by Gottlob Frege, in which existence is not a predicate that applies to objects, but rather to other predicates. Following Frere's line of thinking, and indirectly Kant's ideas, if existence is not a predicate, neither can it be "non-existence" as an attribute of that which does not have existence. Thus, according to Frege, to say of an object that it is non-existent is meaningless and does not respect the syntactic rules of logic. To say that there is an object is the equivalent of saying that the object exists: there is and there exists are equivalents and their formal counterpart is the existential quantifier $\exists$. As a consequence, in the logical tradition founded by Frege, this quantifier possesses "ontological commitment."

If, on the other hand, we want to consider fictional entities as non-existent objects, it would seem that the first modification that we would have to make is to distance ourselves from the Hume-Kant-Frege tradition. That is to say, we would have to consider existence as a predicate that is applicable to certain individuals. In this sense, from the point of view of natural language, we would have to differentiate between the expressions "there are non-existent objects" and "non-existent objects exist." The latter expression is the point of view of philosophers, such as Meinong (Meinong, 1904) and Zalta (Zalta, 1983; 2003), who hold that the expressions "there is" and "there exists" are irreducible to each other. For these thinkers, the assertion "there is an $x$ such that..." is expressed as $\exists . x(\ldots x \ldots)$; and the assertion "an $x$ exists such that..." is expressed as $\exists . x(\mathrm{E} ! x$ Ù...x...), where "E!" corresponds to the predicate "exist." In these expressions the existential quantifier " $\exists$ " does not possess an ontological commitment.

Other thinkers concerned with the non-existent, such as Graham Priest, claim that there is no difference between these two expressions. Both there is and there exists say the same thing and both are ontologically committed. With the help of an ontologically neutral quantifier $(\S)$ and a predicate of existence E, Priest translates "there is (or there exists) something of the color red" the following way: $\S \mathrm{x}(\mathrm{Ex} \& \mathrm{Rx})$ (Priest, 2005, 14). Using this same language, we can say "something 
is red," which is translated as $\S \mathrm{xRx}$ and this does not commit us to the existence of any thing. The same way we can say that "something does not exist" and translate it as: $\S \mathrm{x}(\neg \mathrm{Ex})$.

Hence, in these perspectives that move away from the tradition initiated by Frege, we see how, regardless of the type of quantifier that is used, it is the predicate of existence $\mathrm{E}$ which establishes the distinction between certain things that appear in fictional stories (things that do not exist) and real objects (locatable in space and time). Another interesting option is to reject the use of a predicate of existence but accept that "there are" fictions or that "fictions exist" but in another mode.

With respect to the ontological point of view, there is considerable disagreement among philosophers with regard to the nature of non-existent objects. If they are not found among us as the concrete objects that surround us are, what class of thing are they? There have been various answers to this question, and each one follows a particular philosophical approach: abstract entities, possible entities, non-existent Meinongian, etc. For each and every one the fundamental question is to determine what type of relations are held by the real and concrete objects of our world.

One of the first philosophical papers that dealt with "non-existent objects" was the article by Alexius Meinong, "The theory of objects." In this paper, Meinong proposes a "principle of intentionality" which claims that all mental acts (to think, to inquire, to imagine, to fear, etc.) are characterised by an "intentional directionality." That is to say, every mental act is an act "orientated towards" or "directed towards" an object. But this object, in effect, is not necessarily an existent object. For example, to inquire is always to inquire about something, but sometimes the target of the search does not exist. For example, the adventures of Lope de Aguirre in South America, the Spanish conquistador of the $16^{\text {th }}$ century, who went in search of El Dorado - a city of gold, constitutes one of the most celebrated cases of an act directed towards an inexistent object. Mental acts, hence, can be directed towards things that do not exist, and this calls into question the "principle of intentionality." If Aguirre actions were directed towards an inexistent object, what was that inexistent object towards which his actions were directed? In order to retain the principle of intentionality, some philosophers, such as Brentano (Brentano, 1874) maintain that intentionality is not a relation and, thus, does not require the existence of an object as the target of a mental act.

This all seems to be leading to the question of whether it is necessary to postulate fictions. We say to postulate at the beginning in order to later see if those who postulated believe that what they postulated actually exists here or in other possible worlds, or whether they are dealing with fictional entities in one of these two instances, even though they do not exist. In general terms, we can say that the ontological question is resolved between postulationists and non-postulationists. The latter, armed with Occam's razor, accuse the former of extending ontology 
further than necessary. And this is precisely the point, whether it is necessary or not to postulate these entities and their semantic consequences, among others, to opt for one perspective or the other.

However, having offered an ontological solution to the situation of fictional entities, does not mean having satisfactorily resolved the semantic problems, especially those that concern reference. In some perspectives, semantics precede ontological decisions. The presence of singular fictional terms (names of non-existent objects and characters), continues to be a problem for the semantic analysis of language. One of these problems consists in determining the truth value of negative existential statements. For example, when one claims that "El Dorado does not exist," it seems impossible to deny the existence of an object without falling into contradiction. The reasons for this can be stated as follows: (i) only meaningful statements can be true; (ii) the overall meaning of a statement is based on the meaning of its parts; (iii) if a singular term $\mathrm{k}$ has a meaning, then it denotes or refers to a thing; hence, (iv) if $\mathrm{k}$ denotes or refers to something, the statement "k does not exist" will always be false. In the case of El Dorado, our starting point is the statement "El Dorado does not exist" is true (which seems intuitively reasonable, since such a city has never been found, nor does it seem feasible that such a city will be found in the near future): but, as a result, the statement "El Dorado does not exist" is false, since if it is true, each of its parts must have a meaning, thus El Dorado denotes a thing, and the statement is therefore false. Summing up, either the singular term El Dorado denotes something and the statement is false, or the term El Dorado does not denote anything and the statement is neither true nor false.

One of the solutions to the problem of the negative statements of existence comes from a famous article by Bertrand Russell, "On denoting," considered by many to be the act that gave birth to analytical philosophy. Drawing on newly invented logical instruments - the Frege quantifiers - the solution was to paraphrase statements such as "El Dorado does not exist" such that they are reduced to existentially quantified expressions where the singular terms disappear. The procedure is carried out in two steps:

1. A definite description is attributed to each singular term. For example, the description that is attributed to El Dorado is the following: "The mythical South American city filled with gold and riches."

2. Following the theory of the definite descriptions of Russell, once the singular term is replaced by the description that is attributed to it, the statement "The mythical South American city filled with gold and riches does not exist" is paraphrased as "there is an individual $\mathrm{x}$, such that $\mathrm{x}$ is a mythical South American city full of gold and riches."

With this technique the names of singular terms disappear and the assertions are translated by expressions that begin with an ontologically committed existen- 
tial quantifier within whose scope predicates are located. Let's not forget that for Frege the quantifiers are second-order predicates. Thus, all the expressions with regard to fictional objects will be false except those that deny their existence.

Besides this undesirable consequence, there is another difficulty with regard to singular terms, since it seems that there is no strict connection between the names themselves and the definite descriptions attributed to them. Sometimes we use names without reflecting and without assigning a definite description to them, above all in cases where we do not have one: for example, for certain literary characters of whom we only know their names. In other cases, the description changes, but the name continues to be attributed to the same individual. For example, Aristotle will always be Aristotle even though it is discovered that he was not born in Stagira. That is why it is difficult to offer a strict generalisation about how to apply the paraphrasing technique by means of descriptions.

We must likewise bear in mind that in scientific discourse there are also descriptions devoid of references. For example, the description "the largest natural number." This is a significant gap that Gottlob Frege sought to remedy by stipulating the number 0 as the reference. It is here, in the analysis of fictional discourse, where the limits of Frege's perspective are evident. In effect, certain statements, even though they do not appear in a fictional story, possess a reference. This is the case in historical fiction when we find statements such as "Napoleon is a French general," in which all of the terms possess references. However, Frege would still have refused to give them truth value, but for other reasons. ${ }^{1}$

Another solution to the subject of reference is the explanation of existential assumptions in the semantics of formal languages. From the point of view of classical philosophy, the meaning of singular terms (their contribution to the overall meaning of the statement where they appear) is the object that they denote; and quantifiers are conceived of as having ontological commitment (they refer to existent objects in a domain). Hence, for both singular terms and quantifiers, the semantics of classical logic always presuppose that we are not concerned about anything except existent things.

This presupposition leads to certain principles of classical logic, especially the existential generalisation. In effect, the principle of existential generalisation claims that if it is true that condition $\mathrm{P}$ is applied to an individual $\mathrm{k}$, then it is true that there is a thing to which condition P can be applied. In other words, if condition $\mathrm{P}$ is applied to individual $k$, individual $k$ must exist. Consequently, from a logical point of view, we must seek a perspective that is free of these assumptions, a perspective in which the existential generalisation would be an obstacle. Eliminating this principle, we can develop a logic that has singular terms that do not denote existent things among its syntactic elements. Henri Leonard (Leonard, 1956) and Karel Lambert (Lambert, 2003), among others,

\footnotetext{
${ }^{1}$ For more details, see Stepanians (2007).
} 
have developed fundamental notions in this regard. Indeed, a logic free of these assumptions has been called free logic. Free logic allows us to argue without these restrictions, that is, to include crossed domains in the arguments, in other words, arguments where both entities that exist and entities that do not exist (fictions) come into play at the same time.

John Woods made a major contribution when he published the first logic of fiction in 1974 (Woods, 1974). Although his work was strongly influenced by the intuitions of Meinong, Woods's approach differs significantly from those of the Austrian philosopher. For example, with respect to the notion of an object, Meinong's perspective is broader: fictions are a particular case in a theory that encompasses all objects, with each object having a corresponding description and vice versa. In contrast, Woods's proposal is limited to fictions. It distinguishes between fictional objects and nonesuches. For Meinong each combination of properties corresponded to an object, but for Woods there are certain descriptions that do not refer to anything: the objects to which they seem to refer are nonesuches. Moreover, in several aspects, Woods was the first philosopher to visualise that a fiction could be an impossible entity. For, if we accept fictitious entities, we must also accept that they hold inconsistent or contradictory properties. Therefore, the conceiving of a suitable theory of fiction would require an examination of the rules of logic in question in order to avoid the conclusion that the content of all works of fiction is trivial. This triviality follows from the principle of ex contradictione quodlibet: $\phi \wedge \neg \phi \vdash \omega$, which states that a contradiction discards the possibility of any conclusion. Hence, a logic of fiction must renounce the principles that lead to triviality by using paraconsistent logic. Our contribution to this is to offer a dynamic free logic of fictions from a dialogical perspective, which we shall develop below.

\section{Existential assumptions}

In this part of our inquiry we reviewed the objections (Frege-Russell-Quine) made against the traditional perspectives with respect to the true explanatory power of logic due to the central place of the notion of reference in the semantics of logic. By traditional perspectives, we mean the different free logics that have dealt with the subject of fictions (positive, negative, neutral). Surmounting these objections requires an analysis from a different perspective. For our objective we opted for the pragmatic approach of dialogical logic. In the dialogical approach, a logic of non-existent objects must understand existence by means of the interactional notion of choice. This way of understanding existence is characteristic of dialogical logic, whose semantics is based on the notion of utilisation and can be called pragmatic semantics.

Analyses of traditional logic have the merit of making explicit the metaphysical presuppositions present in the language of logic, but they understand these 
presuppositions as predicates, which contrasts with the pragmatic understanding that dialogical logic proposes. This contrast with traditional interpretations allows for both a static and a dynamic point of view of existence. We postulate that in a dynamic framework it is possible to capture the ontological shifts of status and the indeterminate dimension of certain objects and fictitious characters.

In the tradition associated with Aristotle, there are no empty predicates. This validates the subalternation in the scheme of syllogisms and makes evident the modern reading of categorical judgments through the use of the quantifiers: $\forall \mathrm{x}(\mathrm{Ax} \rightarrow \mathrm{Bx}) \rightarrow \exists \mathrm{x}(\mathrm{Ax} \wedge \mathrm{Bx})$. A logic that accepts this principle as valid, accepts the non-emptiness of predicates as an existential assumption. If we reject this assumption, the subalternation fails. Russell constructed his theory of definite descriptions based on the use of empty predicates; and the solution he proposes for fictions is likewise based on the use of empty predicates. With respect to singular terms, how to make tacit existential presuppositions clear is not so clear. The contribution of Henry S. Leonard (Leonard, 1956) is key to dealing with this point.

The existential presuppositions related to singular terms can be made explicit through the analysis of the following principles of classical logic:

$$
\begin{aligned}
& \forall \mathrm{x} \varphi \rightarrow \varphi[\mathrm{x} / \mathrm{ki}] \text { (Specification) } \\
& \varphi[\mathrm{x} / \mathrm{ki}] \rightarrow \exists \mathrm{x} \varphi \text { (Particularisation) }
\end{aligned}
$$

Any logic that includes these two principles is ontologically committed with respect to its singular terms. One way to free oneself from this commitment is to maintain the reach (classical) of the quantifiers, but broaden the referentiality of the singular terms that lead to a double domain (outer and inner). This would collapse the two principles and validate the following definition of Hintikka (Hintikka, 1966): $\mathrm{E} !(a)=\operatorname{def} \exists \mathrm{x}(\mathrm{x}=a)$. By means of the predicate $\mathrm{E} !$ then the presupposition of existence in the assertions is made explicit. You may also think of a semantic with Meinongian quantifiers, which would yield - following Graham Priest - the following:

"All existent things are such that...»: $\forall \mathrm{x} \alpha[\mathrm{x}]={ }_{\mathrm{df}} \Lambda \mathrm{x}(\mathrm{E} ! \mathrm{x} \rightarrow \alpha[\mathrm{x}])$;

"There exists something such that... $: \exists \mathrm{x} \alpha[x]=_{\mathrm{df}} \Sigma \mathrm{x}(\mathrm{E} ! \mathrm{x} \wedge \alpha[\mathrm{x}])$.

It should be noted that making these presuppositions explicit is given in terms of the relation between the propositions, and this forces us to confront the philosophical difficulties of considering existence as a certain type of property of things. 


\section{Interaction and Logic as a Games: Origins of Another Paradigm}

Within the mathematical logic of the 20th century, a set of techniques, concepts and results emerged and constituted a sort of paradigm in which the idea of logical inference is a particular case of the interaction between the participants of a critical dialogue. As already remarked in the works of Per Martin-Löf (1996), the philosophical vocabulary often presents the following ambiguity: the same term designates both an action and the content or result of such action. This is the case, among others, of "reasoning" and "proposition". Johan van Benthem points out $(1991,159)$ that this ambivalence, which oscillates between a "static" pole (the content) and a "dynamic" pole (the action), confirms the different representations of what the task of logic should be.

For the tradition of mathematical logic that reaches its zenith in Frege's perspective, logic is the study of a structure composed of propositions (independent objects, see Satz an Sich of Bolzano) and of relations between these propositions (the relation of "logical consequence" is the most important). But from the thirties, a new current thinks that the theory of meaning and content of thought (static tradition) must be accompanied by the theory of the act of thinking or giving meaning (dynamic point of view). We can consider the intuitionism of L.E.J. Brouwer as the starting point of this tradition.

The propositional structure that is the object of the static tradition, is defined semantically as a Boolean structure, where propositions are considered as truth values and logical constants as operators on those values. Syntactically, as an algebra of pure signs on which we operate via calculation rules. The existence of such structures is considered a mathematical fact, and its suitability to give the rules of reasoning as evidence. Therefore, in this perspective, in the words of van Benthem:

In other words, the emphasis lies on "that" or "whether" certain statements are true about a situation, not so much on "how" they come to be seen as true. To some, this 'declarative' bias, as opposed to a 'procedural' one, is even a laudable hallmark of logical approaches as such. But, in recent years, there has been a growing tendency in logical and linguistic research to move dynamic considerations of cognitive action to the fore, trying to do justice to the undeniable fact that human cognitive competence consists in procedural facility just as much as communion with eternal truths. (Van Benthem, 1991, 159)

Focusing on "how" statements come to be seen as true has important consequences, both philosophical and technical ${ }^{2}$. It is here, precisely, that intuitionist logic comes into play insofar as it is the first attempt to develop these conse-

\footnotetext{
2 See Rahman/McConaughey/Klev/Clerbout (2018) developed a thorough approach to logic where games of giving and asking questions are extended to games of How.
} 
quences. In fact, there are at least two principles that are considered valid for classical logic but are presented as problematic for those who pretend to consider the mode of apprehension of the truth of a statement by a subject of knowledge: the first is double negation, the second is the law of excluded middle.

The first is the nucleus of a crucial mode of inference in mathematics: reasoning by the absurd. To deduce $A$ from its double negation, according to the intuitionists, generates problems that directly concern the existential quantifier: we can show by the absurd the existence of mathematical entities without the need to exhibit them or build them. The latter, for intuitionists, challenges the significance of the quantifier. If our interest is the mode of apprehension of the truth of a statement, it seems more reasonable to demand that the condition of recognition of the truth of an existential affirmation be the capacity to determine a particular value for a quantified variable, in such a way that the statement of the correctly instantiated formula is true.

With respect to the law of excluded middle, the argument that proves its validity hides a subtlety unacceptable to intuitionists: the demonstration of the principal disjunction is carried out without either of the two members of the disjunction being proven. In this sense the intuitionists argue that it would be reasonable to perform this test by demonstrating at least one member of the disjunction (as the function of a disjunction is defined in the theory of demonstration). As Dummett (1977) points out, if we do not want to consider a theory of truth independently of a theory of the mode of recognition of that truth, the excluded middle is unacceptable since it forces us to consider in a demonstration the existence of demonstration that we do not possess. For all this, the logician who decides to take into account the recognition of truth, in the form of a theory of the construction of demonstrations or an epistemology of the means of verification, is led without delay to modify his conception of the laws of logic, which gives rise to non-classical logics.

However, the development of intuitionist logic encounters a major difficulty of semantic order. For classical propositional logic is provided a notion of semantics developed from the works of Alfred Tarski (1983): theory of models. This theory assumes of the notion of truth via the notion of reference: from a function of interpretation of individual terms and predicates, it is possible to make explicit the value of truth of a statement relative to the structure. But the big problem here is that the Tarskian definition of models presupposes the validity of the third excluded. Therefore, intuitionist logic emerges as a pure calculation without semantics. In this sense, the dialogic logic developed by Paul Lorenzen (1960) and Paul Lorenzen and Kuno Lorenz (1978) arises directly from the intention of giving intuitionist logic a semantics of its own.

In general, we have two traditions that claim to implement the notion of language games in logic. On the one hand, the logic of Lorenzen and Lorenz was born directly from the intention to give intuitionist logic a semantics of its 
own. On the other hand, the semantics of Hintikka games (the GTS = games semantics), which shares the game-theoretical tenets of dialogical logic for logical constants; but turns to standard model theory when we reach the level of elementary statements. At this level standard truth-functional formal semantics comes into play.

More recently Rahman and his team of Lille, in order to develop dialogues with "content" they enriched the dialogical framework with fully interpreted languages (as implemented within Per Martin-Löf's Constructive Type Theory). They call it "Immanent Reasoning" (Rahman et al., 2018). One of the chief ideas animating Immanent Reasoning is that the origin of concepts is rooted not only in games of giving and asking for reasons (games involving Why-questions), but also in games that include moves establishing how it is that the reasons brought forward accomplish their explicative task. Thus, Immanent Reasoning games are dialogical games of Why and How.

\section{Dialogical Logic ${ }^{3}$}

The dialogic approach focuses on the procedural dimension of the demonstration in order to give a semantics to the statements. Indeed, what is at issue here is to know to what extent it is possible that the notion of demonstration, which is normally absent from current linguistic practices, can give semantics to statements. And it is, in fact, in the notion of dialogue that Lorenzen and Lorenz (1978) find the concept that allows them to explain the meaning of logical constants, keeping intact the current linguistic intuitions and stressing the importance of the procedural and epistemic dimension of the notion of demonstration.

Dialogues are mathematically defined language games that establish the interface between the concrete linguistic activity and the formal notion of demonstration. Two interlocutors (Proponent and Opponent) exchange movements that are concretely linguistic acts. The Proponent enunciates a thesis, the thesis of the dialogue, and undertakes to defend it by responding to all the opponent's criticisms. The allowed criticisms are defined in terms of the structure of the statements affirmed in the dialogue. For example, if a player affirms conjunction $\mathrm{A}$ and $\mathrm{B}$, at the same time he gives the opponent the possibility to choose one of the two and to demand that he affirm it. The very notion of asserting is defined by the context of critical interaction: asserting means committing oneself to providing justification to a critical interlocutor. But in dialogues there is no general theory of justification but only insofar as they are logically complex statements that find their justification from simple statements. In turn, simple statements are justified in reciprocal action with the critical interlocutor. That is, as the rule exhorts, the Proponent may consider an elementary statement justified, if and

\footnotetext{
${ }^{3}$ For a more detail presentation see the Appendix at the end of this chapter.
} 
only if the Opponent has granted that justification. This rule confirms the formality of the dialogues: the Proponent wins without presupposing justifications for any particular statement.

A formal dialog (Keiff, 2012) follows two kinds of rules: rules of particles and structural rules according to the following extension of the first-order language:

$\mathrm{FO}[\tau]$, as the result of enriching a first-order language over vocabulary $\tau$ with the following metalogical symbols:

i. two force symbols, ? and !;

ii. the symbols $1,2, \forall x / c, \exists x$ (where $x$ and $c$ stand, respectively, for any variable and any constant of the vocabulary $\tau$ );

iii. two labels, $\mathrm{O}$ and $\mathrm{P}$ (standing for the players, Opponent and Proponent, respectively).

\section{Particle Rules}

The particle rules constitute the local semantics of a logic, for they determine the dialogical meaning of each logical constant. They abstractly describe the way a formula of a given main connective may be objected to (challenge), and how to answer the objection (defence). Particle rules make no reference to the context of argumentation in which the rule is applied. But they are intrinsically dependent on the notion of dialogue, since they describe sequences of language acts. In accordance with the aim of our article, we only present here the rules of the quantifiers:

\begin{tabular}{|c|c|c|}
\hline & Attack & Challenge \\
\hline$X-\forall \mathrm{x}$ & $Y-?_{k i}$ & $X-A[k i / x]$ \\
& The Opponent chooses & \\
\hline$X-\exists \mathrm{x}$ & $Y-?$ & $X-A[k i / x]$ \\
& & The Proponent chooses \\
\hline
\end{tabular}

\section{Structural Rules}

In the same way as particle rules describe the local meaning of the logical constants, structural rules determine their global semantics leading the general organization of the dialogues. The structural rules are meant to organize the 
application of the particle rules in such a way that the set of moves resulting from the application of the rules to an initial formula (called the thesis) yields a dialogue that can be seen as a valid argument for the thesis.

A particular development of both of these rules will be given below for a Targetless Dialogical Logic. For the purpose of our article, we give the rules that determine a propositional logic:

SR-0 (Starting rule): The expressions of a dialogue are numbered, and are alternately stated by $\mathrm{P}$ and $\mathrm{O}$. The thesis is number 0 , and is asserted by $\mathrm{P}$. All moves following the thesis are responses to a move played by another player, and obeying particle rules and other structural rules. $\mathrm{D}_{(\mathrm{A})}$ is called a dialogue that starts with thesis $\mathrm{A}$, even moves are moves made by $\mathrm{P}$, odd moves are made by $\mathrm{O}$.

SR-1cl (Classical game-playing rule): At each move, each player can either challenge a complex formula stated by the other player, or defend himself against any challenge by the other player (including those to which he has already responded).

SR-2 (Branching rule): O generates two separate dialogues when it makes the following choices:

1. Defend a disjunction

2. Challenge a conjunction

3. Respond to the challenge of a conditional

Each of these choices gives a new branch, that is, a new part. However, choices of the Proponent do not generate new branches.

SR-3 (Formal rule): The proponent may not introduce atomic formulas: any atomic formula in a dialogue must first be introduced by the opponent. To challenge atomic formulas is not allowed.

SR-4 (Ranking rule): Opponent and the Proponent successively choose a positive integer called repetition rank. The role of these integers is to ensure that every play ends after finitely many moves by setting the player's repetition rank as the maximum number of times he can challenge or defend against a given move of the other player.

SR-6 Winning Rule: A dialog is closed if, and only if, it contains two occurrences of the same atomic formula, labeled $\mathrm{X}$ and $\mathrm{Y}$ respectively. Otherwise the dialogue remains open. The player who has stated the thesis wins the dialogue if and only if the dialogue is closed. A dialog is finished if and only if it is closed, or if the rules (structural and particle rules) do not allow any other moves. The player who played the role of opponent won the dialogue if and only if the dialogue is finished and open. 
Finished and closed: the proposer wins.

Finished and open: the opponent wins.

Definition of Validity: A thesis A is said to be dialogically valid (in classical or intuitionist logic) when all games of the dialogue $\mathrm{D}_{(\mathrm{A})}$ are closed. ${ }^{4}$

\section{Quantifier as a function of choice (to be is to be chosen)}

For the pragmatic approach we are presenting, the quantifiers are understood as a function of the relation between an action and a proposition. That is, between the action of choosing a constant of substitution and the proposition that results from this action. In these rules there is no forwarding to entities of any kind anywhere. The quantifiers are defined in a dynamic way as actions of choice of individuals by the players. ${ }^{5}$ As can be seen in the table above, the difference between one quantifier and the other is who chooses the ki constant. In fact, when a player proposes a universal affirmation $(X-\forall \mathrm{x})$, it is the other player, the opponent $(Y)$, who chooses the individual $k i$ for the proponent to justify his affirmation. In the case of an existential affirmation, the proposer himself chooses the individual $k i$.

There is an interesting antecedent in the work of Jaśkowski (Jaśkowski, 1934). Jaśkowski speaks of specifying the supposition of a singular term by means of a symbol $\tau$ (tau).

\begin{tabular}{|c|c|c|c|}
\hline \multicolumn{2}{|c|}{$\begin{array}{c}\text { Rules } \delta \\
\text { ki is new }\end{array}$} & \multicolumn{2}{c|}{ Rules $\gamma$} \\
For any ki
\end{tabular}

\footnotetext{
${ }^{4}$ It is possible to prove that the dialogical definition of validity coincides with the standard definition. The first formulations of the evidence were developed by Kuno Lorenz in his PhD thesis (repeated in Lorenzen and Lorenz, 1978). Felscher (1985) proved equivalence with first-order intuitionist logic (by demonstrating the correspondence between intuitionist dialogues and the intuitionist sequent calculus); while Stegmüller (1964) established equivalence in the case of classical first-order logic. Rahman (1993, 88-107), who developed the idea that dialogues for validity could be seen as a theory of evidence structure for constructing tableau systems, directly proved the equivalence between the two types of dialogues and the corresponding semantic tableau, from which the result extends to the corresponding sequent calculus.

${ }^{5}$ For more details, see Fontaine \& Redmond (2012)
} 
Certainly, it can be said here that Dialogic is not a logic but a general framework for performing logics. It is therefore possible to write the rules that make the same set of formulas valid, for example, as classical logic (with winning strategies in Dialogic). Quantifiers can be represented with the same symbol that Russell chose (to recover Frege's original idea), but the semantics that give it meaning rest on the particle rules of the playful semantics provided by the Dialogical Frame. We have then that the set of formulas for which there is a winning strategy in dialogic, coincides with the set of formulas for which, according to Frege, I have the respective tautological truth table that assumes all the semantic commitments of the referentiality for its components (singular and general terms).

In the same way, a logic can be carried out that lets pass only those formulas that would not have ontological commitment if it were a question of the classic quantifiers. For the latter in dialogic, one can see the developments, between others, in Rahman et alii (2018), Redmond (2010) and Fontaine (2013). In fact, in these latest developments it can be seen that the quantifier takes its dynamic nature to the maximum as a function of choice, on the one hand, and on the other, it allows to propose something that in classical perspectives seems impossible: a dynamic quantifier. That is to say, a quantifier that, as a test progresses, updates its ontological commitment.

\section{Ontological Slides and Dynamic Quantifier (CD)}

We call ontological sliding, following the objective of this article, the passage from ontological indetermination to the determination as existing or non-existent. Our proposal is that, from a dialogical point of view, these slippages can be reflected with a single quantifier that we will call dynamic.

The latter is possible, in principle, thanks to the fact that we have two semantic levels in Dialogic: local (particle rules) and global (structural rules) ${ }^{6}$. As can be seen, this is the same quantifier, because the particle rules have not changed. What varies is the global dynamics of the game or structural rules. The latter allows us to establish evidence in a dialogue where we pass from an undetermined status of individuals to an ontologically determined one.

Three notions are required to develop a dynamic quantifier: (i) the notion of symbolic status coming from Hugh MacColl (1906); (ii) that of ontological dependence on the artefactual perspective of Amie Thomasson (1999); and (iii) the definition of introduced constants coming from Frege's Nightmare (Rahman et al. 1997; Rahman 2001).

\footnotetext{
${ }^{6}$ Another favourable consequence of its two levels is that Dialogic is immune to Tonk (Cf. Rahman \& Redmond, 2016).
}

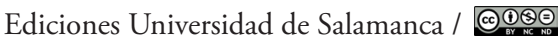

ArtefaCToS, Vol. 9, No. 2 (2020), 2.a Época, 51-77 


\section{(i) Frege's Nightmare and introduced constants}

We propose the following rule ${ }^{7}$ :

Rule of Introduction for the Opponent ${ }^{8}$ : Let us say that singular term $\mathrm{k}_{\mathrm{i}}$ played by $\mathrm{X}$ has been introduced [introduced constants] if:

1. X brings forward $\phi\left[\mathrm{x} / \mathrm{k}_{\mathrm{i}}\right]$ to defend an existential expression of the form $\exists \mathrm{x} \phi$

2. $\mathrm{X}$ attacks $\forall \mathrm{x} \phi$ with $<$ ?- $\mathrm{x} / \mathrm{k}_{\mathrm{i}}>$, where $\mathrm{k}_{\mathrm{i}}$ does not occur in the play before.

In general terms, the notion of introduction makes it possible to recognize those constants that are under the scope of classical or loaded ontologically quantifiers.

\section{(ii) Symbolic status of constants}

The Scottish logician Hugh MacColl (1906) postulates a kind of logic of non-existence that contemplates a symbolic domain of individuals. In effect, he introduced two mutually complementary classes: the class of existing beings $\left(\mathrm{e}_{1}, \mathrm{e}_{2}, \ldots\right)$ and the class of non-existent beings $\left(0_{1}, 0_{2}, \ldots\right)$. But at the same time he speaks of a third class called "symbolic" and the latter would include the two precedents. A symbolic individual could be existing or non-existent (is ontologically underdeterminate).

[symbolic constants]: a symbolic constant is one that appears in the thesis or played by $\mathrm{P}$, but never introduced (by $\mathrm{O}$ ).

\section{(iii) Ontological dependency}

To implement the notion of dependence in dialogic we introduce, then, the predicate of dependency relationship $D$ to which we will give a specific semantics: $D \mathrm{k}_{\mathrm{i}} \mathrm{k}_{\mathrm{j}}\left(\mathrm{k}_{\mathrm{i}}\right.$ depends ontologically on $\mathrm{k}_{\mathrm{j}}$ ). This predicate of dependency was inspired by the work of Amie Thomasson (1999) who proposed it to give identity conditions to non-existent beings. The idea is that if a constant $\mathrm{k}_{\mathrm{i}}$ must count as a nonexistent, it must be inscribed in an ontological dependency relation with respect to a constant $\mathrm{k}_{\mathrm{i}}$ that corresponds to an existing object (independently). This notion helps us to distinguish between existing objects and non-existent objects.

\footnotetext{
7 This addition is based on previous work by Redmond and Fontaine who propose different solutions within the framework of what has been called a dynamic free logic (Redmond, 2010; Redmond and Fontaine, 2011; Fontaine, 2013).

${ }^{8}$ In previous versions (Rahman et al., 1997) only $\mathbf{O}$ could introduce constants.
} 
We take the following convention to show how a dynamic quantifier operates with respect to ontological fluctuations. But it should be noted that the notion of dependency can be used to interpret other types of differences.

$D \mathrm{k}_{\mathrm{i}} \mathrm{k}_{\mathrm{j}} \mathrm{y} \mathrm{k}_{\mathrm{i}}=\mathrm{k}_{\mathrm{j}}$ [reflexivity] if and only if $\mathrm{k}_{\mathrm{i}}\left(\mathrm{k}_{\mathrm{j}}\right)$ designates an existing object (independently).

$D \mathrm{k}_{\mathrm{i}} \mathrm{k}_{\mathrm{j}} \mathrm{y} \mathrm{\textrm {k } _ { \mathrm { i } }} \neq \mathrm{k}_{\mathrm{j}}$ if and only if $\mathrm{k}_{\mathrm{i}}$ is a non-existent one that depends ontologically on $\mathrm{k}_{\mathrm{j}}$ such that $D \mathrm{k}_{\mathrm{i}} \mathrm{k}_{\mathrm{j}}$.

Thus, according to Thomasson, we affirm that non-existent objects are dependent ( $D$ is reflexive) while existing ones are independent.

\section{Symbolic and actualist subdialogues and the dynamic quantifier}

At this point we will consider two levels of dialogues or subdialogues: symbolic subdialogues and actualist subdialogues. This distinction aims to formally capture the idea of a dynamic that is a function of the interpretation of the quantifiers. In effect, we are going to consider only one type of quantifier, but one which changes ontological importance as the proof proceeds. In this sense the quantifiers are presented as having a dynamic ontological commitment: they pass from a stage of ontological indifferentiation (symbolic status) to a more ontologically committed stage. In a symbolic subdialogue, then, the quantifiers behave as possibilist quantifiers to the extent that the variables of substitution correspond to the set of ontologically dependent and ontologically independent objects. Below, in the actualist subdialogue, the constants that substitute in place of the bound variables will correspond only to ontologically independent entities.

The rule governing the passage from one subdialogue to the other is as follows:

The actualist subdialogue, once the symbolic subdialogue has been completed, begins with an attack by $\mathrm{O}$ on the last constant played by $\mathrm{P}$. If the constant comes from the defence of an existential or from having been used by $\mathrm{X}(\mathrm{O}$ or $\mathrm{P})$ to attack a universal quantifier [introduced constant], then $\mathrm{Y}$ has the right to demand that he prove that the dependency relationship of that $\mathrm{k}_{1}$ is reflexive. If the constant has another origin, Y only has the right to ask him what the dependency relation is that he has. 


\begin{tabular}{|c|c|c|}
\hline formula & attack & response \\
\hline $\mathrm{X}-!-A \mathrm{k}_{\mathrm{i}}$ & $\mathrm{Y}-?-D \mathrm{k}_{\mathrm{i}} \mathrm{k}_{\mathrm{j}}$ & $\mathrm{X}-!-D \mathrm{k}_{\mathrm{i}} \mathrm{k}_{\mathrm{j}}$ \\
\hline
\end{tabular}

\begin{tabular}{|c|c|c|c|c|}
\hline \multicolumn{2}{|c|}{$\mathrm{O}$} & \multicolumn{2}{c|}{$\mathrm{P}$} \\
\hline $\mathrm{n}$ & $\mathrm{Ak}_{1}$ & & & \\
\hline $\mathrm{n}+2$ & $D \mathrm{k}_{1} \mathrm{k}_{\mathrm{j}}$ & $\mathrm{n}$ & $?-D \mathrm{k}_{1} \mathrm{k}_{\mathrm{j}}$ & $\mathrm{n}+1$ \\
\hline
\end{tabular}

\begin{tabular}{|c|c|c|c|c|}
\hline \multicolumn{2}{|c|}{$\mathrm{O}$} & \multicolumn{2}{c|}{$\mathrm{P}$} \\
\hline $\mathrm{n}$ & $\mathrm{Ak}_{1}$ & & & \\
\hline $\mathrm{n}+2$ & $D \mathrm{k}_{1} \mathrm{k}_{\mathrm{j}}$ & $\mathrm{n}$ & $?-D \mathrm{k}_{1} \mathrm{k}_{\mathrm{j}}$ & $\mathrm{n}+1$ \\
\hline
\end{tabular}

The latter presupposes the following definitions:

1. We play the symbolic subdialogue with classical rules (ver el conjunto de reglas más arriba).

2. We say that the symbolic dialogue is completed if and only if the dialogue is closed and finished in accordance with the classical rules.

3. Only introduced constants could be represented as having a reflexive dependence.

Basically the challenge consists on asking whether the constants are the same or not. We mean, if the relation $D$ is established between the constant with itself (reflexive) or not.

To show how the dynamic quantifier works, we will take as an example the case of the specification axiom $\left(\mathrm{Ak}_{1} \rightarrow \exists \mathrm{x} A \mathrm{x}\right)$ on which Free Logic is focused (Lambert, 2003). Indeed, in Free Logic this axiom is invalidated because it is considered ontologically committed. That is to say, this axiom demands that the singular terms $\left(\mathrm{k}_{\mathrm{i}}\right)$ refer to entities in the scope of an ontologically loaded quantifier, that is to say, only truths about existing ones can be asserted. We will see how the dynamic quantifier behaves as we have defined it, in order to invalidate this axiom: 


\begin{tabular}{|c|c|c|c|c|c|}
\hline \multicolumn{2}{|c|}{ O } & \multicolumn{2}{c|}{$\mathrm{P}$} \\
\hline & & & & $\mathrm{Ak}_{1} \rightarrow \exists \mathrm{xAx}$ & 0 \\
\hline 1 & $\mathrm{Ak}_{1}$ & 0 & & $\exists \mathrm{xAx}$ & 2 \\
\hline 3 & $?-\exists$ & 2 & & $\mathrm{Ak}_{1}$ & 4 \\
\hline 5 & $?-D \mathrm{k}_{1} \mathrm{k}_{1}$ & $4(3)$ & & & \\
\hline 7 & $D \mathrm{k}_{1} \mathrm{k}_{2} \odot$ & & 1 & $?-D \mathrm{k}_{1} \mathrm{k}_{\mathrm{i}}$ & 6 \\
\hline \multicolumn{5}{|c|}{ Example 1} \\
\hline
\end{tabular}

Indeed, we can see here that in the first (symbolic) subdialogue the proof of the axiom is easily reached while in the actualist subdialogue there is no winning strategy for it, i.e. the formula has acceptance when there is no precision about the status of $\mathrm{k} 1$ 's reference, while in the second subdialogue it is clear that the formula is only correct for existing entities (with reflexive dependence) and therefore has no winning strategy ( $\mathrm{O}$ wins).

If that same constant had already been introduced by $\mathrm{O}$ (see rule above), then you should grant the reflexivity of the constant to P. See the following example:

\begin{tabular}{|c|c|c|c|c|c|}
\hline \multicolumn{2}{|c|}{$\mathrm{O}$} & \multicolumn{2}{c|}{$\mathrm{P}$} \\
\hline & & & & $\exists \mathrm{xAx} \rightarrow \exists \mathrm{xAx}$ & 0 \\
\hline 1 & $\exists \mathrm{xAx}$ & & & $\exists \mathrm{xAx}$ & 2 \\
\hline 3 & $?-\exists$ & 2 & & $\mathrm{Ak}_{1}$ & 6 \\
\hline 5 & $\mathrm{Ak}_{1}$ & & 1 & $?-\exists$ & 4 \\
\hline 5 & $?-D \mathrm{k}_{1} \mathrm{k}_{1}$ & $6(2)$ & & $D \mathrm{k}_{1} \mathrm{k}_{1} \odot$ & 8 \\
\hline 7 & $D \mathrm{k}_{1} \mathrm{k}_{1}$ & & 5 & $?-D \mathrm{k}_{1} \mathrm{k}_{1}$ & 6 \\
\hline \multicolumn{5}{|c|}{ Example 2 } \\
\hline
\end{tabular}

In example 1 it can be clearly seen how the quantifier moves dynamically from a symbolic commitment to constants to a classical commitment. That is, in the first part, $\mathrm{k} 1$ could be both an existing and a non-existent one and does not affect the development of the proof. But in the second part, when $\mathrm{O}$ asks about the dependency assumptions put into play, it is clear that the statement is only correct for existing. In example 2, on the contrary, we pass from the ontological indetermination of $\mathrm{k} 1$ in the first part to its determination as existing (as an in- 
stantiation to close the test). In both cases, in fact, we are dealing with the same quantifier that dynamically adjusts its ontological commitment throughout the proof.

\section{Conclusion}

Although this proposal has not yet been fully consummated, it has demonstrated, on one hand, the importance of taking the notion of choice into account to overcome the use of the predicate of existence; and, on the other hand, the possibility of considering a dynamic quantifier that is capable of capturing ontological slides through an argument. In the context of dialogical logic, existence is considered to be a function of choice that is determined by the application of logical rules, and not just as a static property expressed by a predicate of existence. And if dialogical logic is so efficacious in this regard, it is most likely because it allows us to deal with the problems in a context that establishes links between logical, pragmatic, and epistemic considerations.

One may be deceived by the similarities between predicate 'E!' and predicate 'D', but these two predicates do not express the same thing and do not function the same way. Predicate E! is a primitive that is neither made explicit nor justified, and thus does nothing more than make the existential suppositions explicit in a static manner. In contrast, the meaning of $\mathrm{D}$ comes to the fore as the attacks and responses take place that depend on the application of logical rules in the course of a dialogue. In this sense D makes certain choices explicit as well as the relations that maintain the fictions with real entities. Thus, the relationship of dependence expressed by " $\mathrm{D}$ " allows us to conceive a division inside the domain. 


\section{Appendix: Standard Dialogical Logic ${ }^{9}$}

Let $\mathrm{L}$ be a first-order language built as usual upon the propositional connectives, the quantifiers, a denumerable set of individual variables, a denumerable set of individual constants and a denumerable set of predicate symbols (each with a fixed arity).

We extend the language $\mathrm{L}$ with two labels $\mathrm{O}$ and $\mathrm{P}$, standing for the players of the game, and the question mark '?'. When the identity of the player does not matter, we use variables $\mathrm{X}$ or $\mathrm{Y}$ (with $\mathrm{X} \neq \mathrm{Y}$ ). A move is an expression of the form 'X-e' here $e$ is either a formula $\varphi$ of $\mathrm{L}$ or the form '? $\left[\varphi_{1}, \ldots, \varphi_{\mathrm{n}}\right]$ '.

We now present the rules of dialogical games. There are two distinct kinds of rules named particle (or local) rules and structural rules. We start with the particle rules.

\begin{tabular}{|c|c|c|c|c|}
\hline Previous move & $\mathrm{X}-\varphi \wedge \psi$ & $\mathrm{X}-\varphi \vee \psi$ & $\mathrm{X}-\varphi \rightarrow \psi$ & $\mathrm{X}-\neg \varphi$ \\
\hline Challenge & $\begin{array}{c}\mathrm{Y}-?[\varphi] \text { or } \\
\mathrm{Y}-?[\psi]\end{array}$ & $\mathrm{Y}-?[\varphi, \psi]$ & $\mathrm{Y}-\varphi$ & $\mathrm{Y}-\varphi$ \\
\hline Defence & $\begin{array}{c}\mathrm{X}-\varphi \\
\text { resp. X- }-\psi\end{array}$ & $\begin{array}{c}\mathrm{X}-\varphi \\
\text { or X- }-\psi\end{array}$ & $\mathrm{X}-\psi$ & -- \\
\hline
\end{tabular}

\begin{tabular}{|c|c|c|}
\hline Previous move & $\mathrm{X}-\forall \mathrm{x} \varphi$ & $\mathrm{X}-\exists \mathrm{x} \varphi$ \\
\hline Challenge & $\mathrm{Y}-?[\varphi(\mathrm{a} / \mathrm{x})]$ & $\mathrm{Y}-?\left[\varphi\left(\mathrm{a}_{1} / \mathrm{x}\right), \ldots, \varphi\left(\mathrm{a}_{\mathrm{n}} / \mathrm{x}\right)\right]$ \\
\hline Defence & $\mathrm{X}-\varphi(\mathrm{a} / \mathrm{x})$ & $\begin{array}{c}\mathrm{X}-\varphi\left(\mathrm{a}_{\mathrm{i}} / \mathrm{x}\right) \\
\text { with } 1 \leq \mathrm{i} \leq \mathrm{n}\end{array}$ \\
\hline
\end{tabular}

In this table, the $\mathrm{a}_{\mathrm{i}} \mathrm{s}$ are individual constants and $\varphi\left(\mathrm{a}_{\mathrm{i}} / \mathrm{x}\right)$ denotes the formula obtained by replacing every occurrence of $x$ in $\varphi$ by $a_{i}$. When a move consists in a question of the form '? $\left[\varphi_{1}, \ldots, \varphi_{n}\right]$ ', the other player chooses one formula

\footnotetext{
9 The following brief presentation of standard dialogical logic is due to Nicolas Clerbout. The main original papers on dialogical logic are collected in Lorenzen and Lorenz (1978). For a historical overview see Lorenz (2001). Other papers have been collected more recently in Lorenz (2008, 2010a, b). A detailed account of recent developments since, say, Rahman (1993) and Felscher (1994), can be found in Rahman and Keiff (2005) and Keiff (2009). For the underlying metalogic see Clerbout (2013a; 2013b). For a textbook presentation: Redmond and Fontaine (2011) and Rückert (2011a). For the key role of dialogic in regaining the link between dialectics and logic, see Rahman and Keiff (2010). Fiutek et al. (2010) study the dialogical approach to belief revision. Redmond (2010) studied Dialogic and fiction. Clerbout, Gorisse and Rahman (2011) studied Jain Logic in the dialogical framework. Popek (2012, 223-244) develops a dialogical reconstruction of medieval obligationes. See also Magnier (2013) - on dynamic epistemic logic and legal reasoning in a dialogical framework.
} 
among $\varphi_{1}, \ldots, \varphi_{\mathrm{n}}$ and plays it. We can thus distinguish between conjunction and disjunction on the one hand, and universal and existential quantification on the other hand, in terms of which player has a choice. In the cases of conjunction and universal quantification, the challenger chooses which formula he asks for. Conversely, in the cases of disjunction and existential quantification, the defender is the one who can choose between various formulas. Notice that there is no defence in the particle rule for negation.

Particle rules provide an abstract description of how the game can proceed locally: they specify the way a formula can be challenged and defended according to its main logical constant. In this way we say that these rules govern the local level of meaning. Strictly speaking, the expressions occurring in the table above are not actual moves because they feature formulas schemata and the players are not specified. Moreover, these rules are indifferent to any particular situation that might occur during the game. For these reasons we say that the description provided by the particle rules is abstract. The words "challenge" and "defence" are convenient to name certain moves according to their relationship with other moves. Such relationships can be precisely defined in the following way. Let $\Sigma$ be a sequence of moves. The function $p_{\Sigma}$ assigns a position to each move in $\Sigma$, starting with 0 . The function $F_{\Sigma}$ assigns a pair $[m, Z]$ to certain moves $N$ in $\Sigma$, where $m$ denotes a position smaller than $p_{\Sigma}(N)$ and $Z$ is either $C$ or $D$, standing respectively for "challenge" and "defence". That is, the function $F_{\Sigma}$ keeps track of the relations of challenge and defence as they are given by the particle rules. A play (or dialogue) is a legal sequence of moves, i.e., a sequence of moves which observes the game rules. The rules of the second kind that we mentioned, the structural rules, give the precise conditions under which a given sentence is a play. The dialogical game for $\varphi$, written $\mathrm{D}(\varphi)$, is the set of all plays with $\varphi$ as the thesis (see the Starting rule below). The structural rules are the following:

SR0 (Starting rule): Let $\varphi$ be a complex formula of L. For every $\pi \in \mathrm{D}(\varphi)$ we have:

- $p_{\pi}(\mathrm{P}-\varphi)=0$,

- $p_{\pi}(\mathrm{O}-\mathrm{n}:=i)=1$,

- $\quad p_{\pi}(\mathrm{P}-\mathrm{m}:=j)=2$.

In other words, any play $\mathrm{p}$ in $\mathrm{D}(\varphi)$ starts with $\mathrm{P}-\varphi$. We call $\varphi$ the thesis of the play and of the dialogical game. After that, the Opponent and the Proponent successively choose a positive integer called repetition rank. The role of these integers is to ensure that every play ends after finitely many moves, in a way specified by the next structural rule. 


\section{SR1 (Classical game-playing rule):}

- Let $\pi \in \mathrm{D}(\varphi)$. For every $M$ in $\pi$ with $p_{\pi}(M)>2$ we have $F_{\pi}(M)=\left[m^{\prime}, Z\right]$ with $m^{\prime}<p_{\pi}(M)$ and $Z \in\{C, D\}$

- Let $r$ be the repetition rank of player $\mathrm{X}$ and $\pi \in \mathrm{D}(\varphi)$ such that

- the last member of $\pi$ is a $\mathrm{Y}$ move,

- $M_{0}$ is a $\mathrm{Y}$ move of position $m_{0}$ in $\pi$,

$-M_{1}, \ldots, M_{\mathrm{n}}$ are X moves in $\pi$ such that $F_{\pi}\left(M_{1}\right)=\ldots=F_{\pi}\left(M_{\mathrm{n}}\right)=\left[m_{0}, Z\right]$.

Consider the sequence ${ }^{10} \pi^{\prime}=\pi^{*} N$ where $N$ is an $\mathrm{X}$ move such that $\mathrm{F}_{\pi^{\prime}}(N)=\left[m_{0}, Z\right]$. We have $\pi^{\prime} \in \mathrm{D}(\varphi)$ only if $\mathrm{n}<r$.

The first part of the rule states that every move after the choice of repetition ranks is either a challenge or a defence. The second part ensures the finiteness of plays by setting the player's repetition rank as the maximum number of times he can challenge or defend against a given move of the other player.

SR2 (Formal rule): Let $\psi$ be an elementary sentence, $N$ be the move P- $\psi$ and $M$ be the move O- $\psi$. A sequence $\pi$ of moves is a play only if we have: if $N \in \pi$ then $M \in \pi$ and $p_{\pi}(M)<p_{\pi}(N)$.

A play is called terminal when it cannot be extended by further moves in compliance with the rules. We say it is X terminal when the last move in the play is an $\mathrm{X}$ move.

SR3 (Winning rule): Player $\mathrm{X}$ wins the play $\pi$ only if it is $\mathrm{X}$ terminal.

Consider for example the following sequences of moves: $\mathrm{P}-\mathrm{Qa} \rightarrow \mathrm{Qa}, \mathrm{O}-\mathrm{n}:=1$, $\mathrm{P}-\mathrm{m}:=12, \mathrm{O}-\mathrm{Q} a, \mathrm{P}-\mathrm{Q}$.

We often use a convenient table notation for plays. For example, we can write this play as follows:

\begin{tabular}{|c|c|c|c|c|}
\hline & $\mathrm{O}$ & & $\mathrm{P}$ & \\
\hline & & & $\mathrm{Qa} \rightarrow \mathrm{Qa}$ & 0 \\
\hline 1 & $\mathrm{n}:=1$ & & $\mathrm{~m}:=12$ & 2 \\
\hline 3 & $\mathrm{Qa}$ & $(0)$ & $\mathrm{Qa}$ & 4 \\
\hline
\end{tabular}

The numbers in the external columns are the positions of the moves in the play. When a move is a challenge, the position of the challenged move is indicated in the internal columns, as with move 3 in this example. Notice that such tables carry the information given by the functions $p$ and $F$ in addition to representing the play itself.

\footnotetext{
${ }^{10}$ We use $\pi * N$ to denote the sequence obtained by adding move $N$ to the play $\pi$.
} 
However, when we want to consider several plays together - or example when building a strategy - such tables are not that perspicuous. So we do not use them to deal with dialogical games for which we prefer another perspective. The extensive form of the dialogical game $\mathrm{D}(\varphi)$ is simply the tree representation of it, also often called the game-tree. More precisely, the extensive form $\mathrm{E}_{\varphi}$ of $\mathrm{D}(\varphi)$ is the tree $(T, l, S)$ such that:

i. Every node $t$ in $T$ is labelled with a move occurring in $\mathrm{D}(\varphi)$

ii. $\quad l: T \rightarrow \mathrm{N}$

iii. $S \subseteq T^{2}$ with:

- There is a unique $t_{0}$ (the root) in $T$ such that $l\left(t_{0}\right)=0$, and $t_{0}$ is labelled with the thesis of the game.

- For every $t \neq t_{0}$ there is a unique $t^{\prime}$ such that $t^{\prime} S t$.

- For every $t$ and $t^{\prime}$ in $T$, if $t S t^{\prime}$ then $l(t)=l(t)+1$.

- Given a play $\pi$ in $\mathrm{D}(\varphi)$ such that $p_{\pi}(M)=p_{\pi}(M)+1$ and $t, t^{\prime}$ respectively labelled with $M$ and $M^{\prime}$, then $t S t$.

A strategy for Player $\mathrm{X}$ in $\mathrm{D}(\varphi)$ is a function that assigns an $\mathrm{X}$ move $M$ to every non terminal play $\pi$ with a $Y$ move as the last member such that extending $\pi$ with $M$ results in a play. An X strategy is winning if playing according to it leads to X's victory no matter how $Y$ plays.

A strategy can be considered from the viewpoint of extensive forms: the extensive form of an X strategy $\sigma$ in $\mathrm{D}(\varphi)$ is the tree-fragment $\mathrm{E}_{\varphi, \sigma}=\left(T_{\sigma}, l_{\sigma}, S_{\sigma}\right)$ of $\mathrm{E}_{\varphi}$ such that:

i. The root of $\mathrm{E}_{\varphi, \sigma}$ is the root of $\mathrm{E}_{\varphi}$.

ii. Given a node $t$ in $\mathrm{E}_{\varphi}$ labelled with an $\mathrm{X}$ move, we have that $t S_{\sigma} t^{\prime}$ whenever $t S t$.

iii. Given a node $t$ in $\mathrm{E}_{\varphi}$ labelled with a $\mathrm{Y}$ move and with at least one $t^{\prime}$ such that $t S t$, then there is a unique $\sigma(t)$ in $T_{\sigma}$ where $t S_{\sigma} \sigma(t)$ and $s(t)$ is labelled with the $\mathrm{X}$ move prescribed by $\sigma$.

Here are some examples of results which pertain to the level of strategies. ${ }^{11}$

- Winning P strategies and leaves. Let $\mathrm{w}$ be a winning P strategy in $\mathrm{D}(\varphi)$. Then every leaf in $\mathrm{E}_{\varphi, \omega}$ is labelled with a P signed atomic sentence.

- Determinacy. There is a winning X strategy in $\mathrm{D}(\varphi)$ if and only if there is no winning $Y$ strategy in $\mathrm{D}(\varphi)$.

11 These results are proven, together with others, in Clerbout (2013b). 
- Soundness and Completeness of Tableaux. Consider first-order tableaux and first-order dialogical games. There is a tableau proof for $\varphi$ if and only if there is a winning P strategy in $\mathrm{D}(\varphi)$.

By soundness and completeness of the tableau method with respect to model-theoretical semantics, it follows that existence of a winning P strategy coincides with validity: There is a winning P strategy in $\mathrm{D}(\varphi)$ if and only if $\varphi$ is valid.

\section{References}

Benthem, Johan van (1991). General Dynamics. Theoretical Linguistics, 17(1-3),159202.

Brentano, F. (1874). Psychologie vom empirischen Standpunkt. Leipzig: Duncke \& Humblot.

Clerbout, Nicolas (2013a). Etude sur quelques sémantiques dialogiques. Concepts fondamentaux et éléments de metathéorie. PHD thesis, Lille/Leiden: Universities of Lille 3 and Leiden.

Clerbout, Nicolas (2013b). First-Order Dialogical games and Tableaux. Journal of Philosophical Logic, 43, 785-801. https://doi.org/10.1007/s10992-013-9289-z

Clerbout, Nicolas; Gorisse, Marie-Hélène; Rahman, Shahid (2011). Context-sensitivity in Jain Philosophy. A dialogical study of Siddharsigani's Commentary on the Handbook of Logic. Journal of Philosophical Logic, 40(5), 633-662.

Dummett, Michael (1977). Elements of Intuitionism. Oxford: Oxford University Press.

Felscher, W. (1994). Review of Jean E. Rubin's Mathematical logic: applications and theory. The Journal of Symbolic Logic, 59, 670-671.

Fiutek, V., Rückert, H., Rahman, S. (2010). A Dialogical Semantics for Bonanno's System of Belief Revision. In P. Bour et al (eds.), Constructions (pp. 315-334). London: College Publications.

Fontaine, M. (2013). Argumentation et engagement ontologique de l'acte intentionnel. Pour une réflexion critique sur l'identité dans les logiques intentionnelles explicites. PHD thesis, Lille: University of Lille 3.

Fontaine, Matthieu, Redmond, Juan (2012). To Be is To Be Chosen - A Dialogical Understanding of Ontological Commitment. In C. Barés Gomez, S. Magniez and F. Salguero (eds.), Logic of Knowledge. Theory and Applications. Serie Dialogues (pp. 203-222). London: College Publications.

Hintikka, Jaakko (1966). On the Logic of Existence and Necessity I: Existence. The Monist, 50, 55-76.

Hume, David (2000). A Treatise of Human Nature. Edited by David Fate Norton and Mary J. Norton. Oxford: Oxford University Press.

Jaśkowski, S. (1934). On the rules of supposition in formal logic. Studia Logica, 1, 5-32. 
Kant, Immanuel, (1781/1789). Kritik der reinen Vernunft. (ed. Wilhelm Weischedel), Darmstadt: Wissenschaftliche Buchgesellschaft.

Keiff, L. (2009). Dialogical Logic. Available at Sanford Encyclopedia of Philosophy, online (accessed 2013).

Keiff, Laurent (2012). Dialogical Logic. The Stanford Encyclopedia of Philosophy (Summer 2011 Edition), Edward N. Zalta (ed.). https://plato.stanford.edu/ archives/sum2011/entries/logic-dialogical/

Lambert, Karel (2003). Free Logic: Selected Essays. Cambridge \& New York: Cambridge University Press.

Leonard, Henri S. (1956). The logic of existence. Philosophical Studies, VII(4), 49-64.

Lorenzen, Paul and Lorenz, Kuno (1978). Dialogische Logik. Darmstadt: Wissenschaftliche Buchgesellschaft.

Lorenzen, Paul (1960). Logik und Agon. In Atti del XII Congresso Internationale de Filosofia (Venezia): Logica, linguaggio e comunicazione Volume 4 (pp. 187-194).

MacColl, Hugh. (1906). Symbolic Logic and its Applications. London/New York/ Bombay: Longmans, Green \& Co.

Magnier, S. (2013). Approche dialogique de la dynamique épistémique et de la condition juridique. London: College Publications.

Martin-Löf, Per (1996). On the Meanings of the Logical Constants and the Justifications of the Logical Laws. Nordic Journal of Philosophical Logic, 1(1), 11-60.

Meinong, Alexius (1904). Über Gegenstandstheorie. In A. Meinong (1971), Abhandlungen zur Erkenntnistheorie und Gegenstandstheorie, II, (R. Haller ed.; pp. 481-535). Graz: Akademische Druck- u. Verlagsanstalt.

Popek, A. (2012). Logical dialogues from Middle Ages. In C. Barés et al (eds.), Logic of Knowledge. Theory and Applications (pp. 223-244). London: College Publications.

Priest, Graham (2005). Towards Non-Being. The logic and Metaphysics of Intentionality. Oxford: Clarendon Press.

Rahman, S., Fishmann, M., Rückert, H. (1997). On Dialogues and Ontology. The Dialogical Approach to Free Logic. Logique et Analyse, 40(160), 357-374.

Rahman, Shahid \& Redmond, Juan (2016). Armonía Dialógica: “tonk”, Teoría Constructiva de Tipos y Reglas para Jugadores Anónimos. THEORIA, 31(1), $27-53$.

Rahman, Shahid and Keiff, Laurent (2005). On How to be a Dialogician. In D. Vanderveken (ed.), Logic, Thought and Action (pp. 359-4089). Dordrecht: Kluwer.

Rahman, Shahid and Keiff, Laurent (2010). La Dialectique entre logique et rhétorique. Revue de Métaphysique et de Morale, 66(2), 149-178.

Rahman, Shahid (1993). Über Dialogue, Protologische Kategorien und andere Seltenheiten. Frankfurt/Paris/New York: P. Lang. 
Rahman, Shahid; McConaughey, Zoe; Klev, Ansten and Clerbout, Nicolas (2018). Immanent Reasoning or Equality in Action. A Plaidoyer for the Play Level. Series Logic, Argumentation \& Reasoning, vol. 18. Cham: Springer.

Redmond, Juan and Fontaine, Matthieu (2011). How to Play Dialogues: An Introduction to Dialogical Logic. London: College Publications.

Redmond, Juan (2010). Logique dynamique de la fiction. Pour une approche dialogique. London: College Publications.

Stepanians, Markus (2007). Gottlob Frege. Una introducción. (trad. Juan Redmond). In Cuadernos de Lógica, Epistemología y Lenguaje, vol. 1. London: College Publications.

Tarski, Alfred (1983). Logic, Semantics, Metamathematics. Indianapolis: Hackett.

Thomasson, Amie L. (1999). Fiction and Metaphysics. Cambridge: Cambridge University Press.

Woods, John (1974). The Logic of Fiction. A Philosophical Sounding of Deviant Logic. La Haye: Mouton.

Zalta, Edward (1983). Abstract Objects. The Netherlands: Reidel.

Zalta, Edward (2003). Referring to Fictional Characters. Dialectica, 57, 243-54. 